\title{
Elemental Migration in Core/Shell Structured Lanthanide Doped Nanoparticles
}

Lu Liu, ${ }^{1}$ Xiaomin Li, ${ }^{1 *}$ Yong Fan, ${ }^{1}$ Changyao Wang, ${ }^{1}$ Ahmed Mohamed El-Toni, ${ }^{2}$ Mansour Saleh Alhoshan, ${ }^{3}$ Dongyuan Zhao, ${ }^{1}$ Fan Zhang ${ }^{1 *}$

${ }^{1}$ Department of Chemistry, Shanghai Key Laboratory of Molecular Catalysis and Innovative Materials, State Key Laboratory of Molecular Engineering of Polymers and iChem, Fudan University, Shanghai 200433, P. R. China.

${ }^{2}$ King Abdullah Institute for Nanotechnology, King Saud University, Riyadh 11451, Saudi Arabia.

${ }^{3}$ Department of Chemical Engineering, King Saud University, Riyadh 11421, Saudi Arabia.

E-mail: zhang_fan@fudan.edu.cn; lixm@fudan.edu.cn. 


\section{Supporting Information:}

\section{Experimental Section}

\section{Synthesis of $\beta$ - $\mathrm{NaY}(\mathrm{Er}) \mathrm{F}_{4}$ Core Nanoparticles:}

Hexagonal phase $\mathrm{NaY}(\mathrm{Er}) \mathrm{F}_{4}$ nanocrystals were synthesized following a previously reported thermolysis method. ${ }^{[1]} \mathrm{In}$ a typical synthesis, $\mathrm{Y}(\mathrm{Er}) \mathrm{Cl}_{3} \cdot 6 \mathrm{H}_{2} \mathrm{O}(1.0 \mathrm{mmol}), \mathrm{OA}$ $(6.0 \mathrm{~mL})$ and $\mathrm{ODE}(15.0 \mathrm{~mL})$ were mixed together and heated to $140{ }^{\circ} \mathrm{C}$ under vacuum until a clear solution formed, after that, the solution was cooled down to room temperature. Then, a methanol solution $(10.0 \mathrm{~mL})$ of ammonium fluoride $(4.0 \mathrm{mmol})$ and sodium hydroxide $(2.5 \mathrm{mmol})$ was added and stirred for $1 \mathrm{~h}$. The reaction mixture was then heated to $70{ }^{\circ} \mathrm{C}$ and maintained for half an hour to remove the methanol. Afterward, the solution was heated to $290{ }^{\circ} \mathrm{C}\left(\sim 10^{\circ} \mathrm{C} / \mathrm{min}\right)$ and maintained for $60 \mathrm{~min}$ under a gentle argon flow. Then, the solution was cool down to room temperature. The nanoparticles were centrifuged and washed twice with ethanol and finally dispersed in $10 \mathrm{~mL}$ of cyclohexane for further use.

\section{Synthesis of $\beta-N a Y F 4: 30 \% G d, 25 \% Y b, 2 \% H o$ core nanoparticles:}

Hexagonal phase $\mathrm{NaYF}_{4}: \mathrm{Gd}, \mathrm{Yb}$,Ho nanocrystals were synthesized following a previously reported thermolysis method. ${ }^{[1]}$ Calculated amounts of $\mathrm{LnCl}_{3} \cdot 6 \mathrm{H}_{2} \mathrm{O}$ to a total of $1.0 \mathrm{mmol}$, In a typical synthesis, OA $(6.0 \mathrm{~mL})$ and ODE $(15.0 \mathrm{~mL})$ were mixed together and heated to $140{ }^{\circ} \mathrm{C}$ under vacuum until a clear solution formed, after that, the solution was cooled down to room temperature. To this solution at room temperature, a methanol solution $(10.0 \mathrm{~mL})$ of ammonium fluoride $(4 \mathrm{mmol})$ and sodium hydroxide $(2.5 \mathrm{mmol})$ was added and stirred for $1 \mathrm{~h}$. The reaction mixture was then heated to $70{ }^{\circ} \mathrm{C}$ and maintained for half an hour to remove the methanol. Afterward, the solution was heated to $300{ }^{\circ} \mathrm{C}\left(\sim 10{ }^{\circ} \mathrm{C} / \mathrm{min}\right)$ and maintained for 60 min under a gentle argon flow. Then, the solution was cool down to room temperature and the nanoparticle products were centrifuged and washed twice with ethanol. The nanoparticles were finally dispersed in $10 \mathrm{~mL}$ of cyclohexane for further use.

Synthesis of $\beta-N a Y F 4: 30 \% G d, 25 \% \mathrm{Yb}, 2 \mathrm{Er}$ core nanoparticles: 
The synthesis of the $\mathrm{NaYF}_{4}: \mathrm{Gd}, \mathrm{Yb}$,Er nanoparticles was similar to that of the $\mathrm{NaYF}_{4}: \mathrm{Gd}, \mathrm{Yb}$,Ho core nanoparticles except $0.02 \mathrm{mmol}$ of $\mathrm{ErCl}_{3}$ were used instead of $\mathrm{HoCl}_{3}$.

\section{Synthesis of $\beta-N a G d F 4: 25 \% Y b, 0.5 \% T m$ core nanoparticles:}

The synthesis of the $\mathrm{NaGdF}_{4}: \mathrm{Yb}, \mathrm{Tm}$ nanoparticles was similar to that of the $\mathrm{NaYF}_{4}: \mathrm{Gd}, \mathrm{Yb}$,Ho core nanoparticles except $\mathrm{LnCl}_{3}(\mathrm{Ln}=\mathrm{Gd}, \mathrm{Yb}, \mathrm{Tm})$ were used.

\section{Characterization.}

Transmission electron microscopy (TEM), high-resolution transmission electron microscopy (HRTEM), high-angle annular dark field scanning transmission electron microscopy (HAADF-STEM) observations were performed with a JEM-2100F with an accelerating voltage of $200 \mathrm{kV}$ equipped with a post column Gatan imaging filter (GIFTri-dium). The emission spectra were obtained on an Edinburgh Instruments FLS980 fluorescence spectrometer (unless otherwise specified, all spectra were collected under identical experimental conditions). X-ray photoelectron spectroscopy (XPS) spectra were performed with a Kratos AXIS UltraDLD, using a mono Al K $\alpha$ X-ray source $(1486.71 \mathrm{eV})$. X-ray diffraction (XRD) analysis was carried out on a Bruker D8 diffractometer with the $\mathrm{Cu} \mathrm{K \alpha}$ line at $40 \mathrm{kV}$ and $20 \mathrm{~mA}$. 


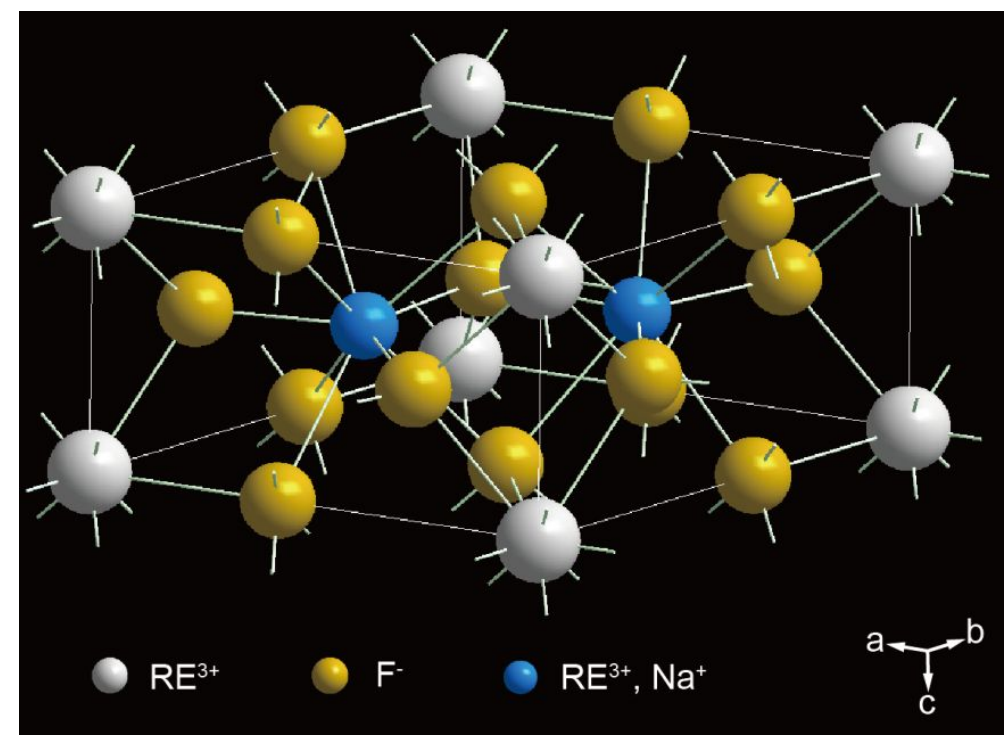

Scheme S1. Schematic presentation of hexagonal-phase crystal $\mathrm{NaREF}_{4}$ structures. In this hexagonal phase, an ordered array of $\mathrm{F}^{-}$ions offers two types of cation sites: one site occupied by $\mathrm{RE}^{3+}$ and the other occupied randomly by $\mathrm{RE}^{3+}$ and $\mathrm{Na}^{+}$. The coordination number of lanthanides in this crystal is nine.

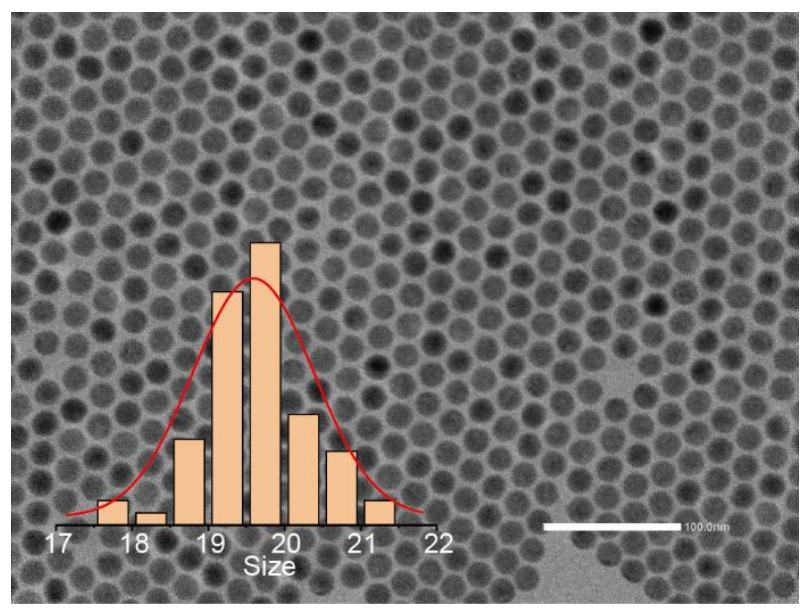

Figure S1. TEM image and the corresponding size distribution (insert) of the obtained $\mathrm{NaErF}_{4}$ core nanoparticles. 

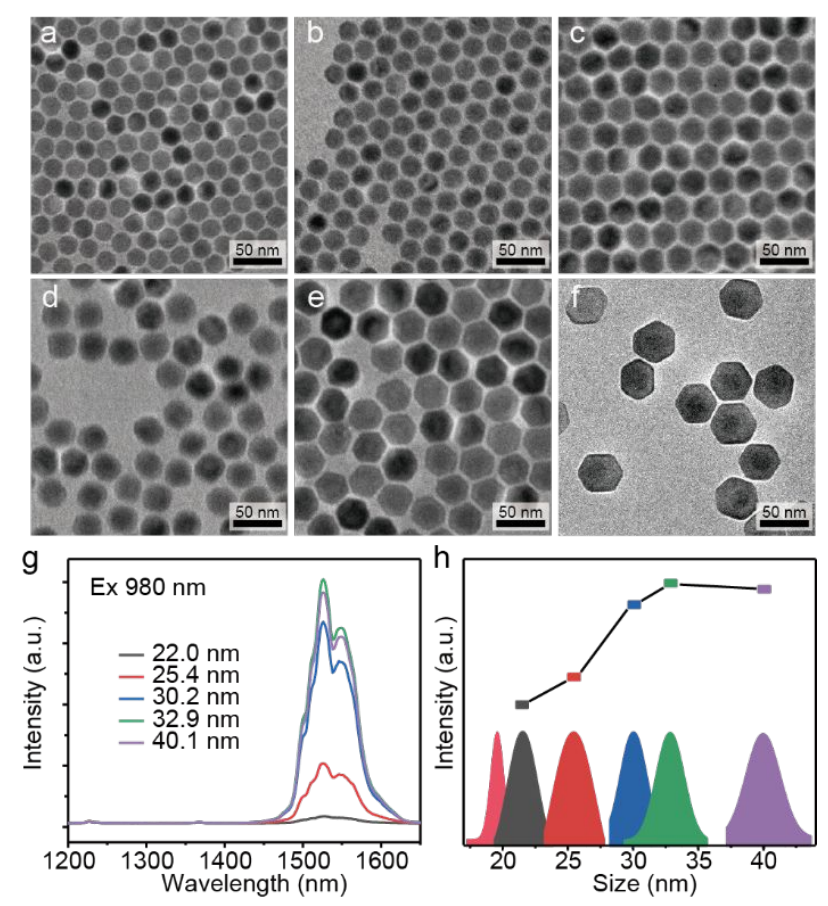

Figure S2. TEM images of the $\mathrm{NaErF}_{4}$ core (a) and $\mathrm{NaErF}_{4} @ \mathrm{NaYF}_{4}$ core/shell nanoparticles with different shell thickness (b, $22.0 \mathrm{~nm}$; c, $25.4 \mathrm{~nm}$; d, $30.2 \mathrm{~nm}$; e, 32.9 nm; f, $40.1 \mathrm{~nm}) .(\mathrm{g}, \mathrm{h})$ Emission spectra of the $\mathrm{NaErF}_{4} @ \mathrm{NaYF}_{4}$ core/shell nanoparticles with different shell thickness under $980 \mathrm{~nm}$ excitation. 


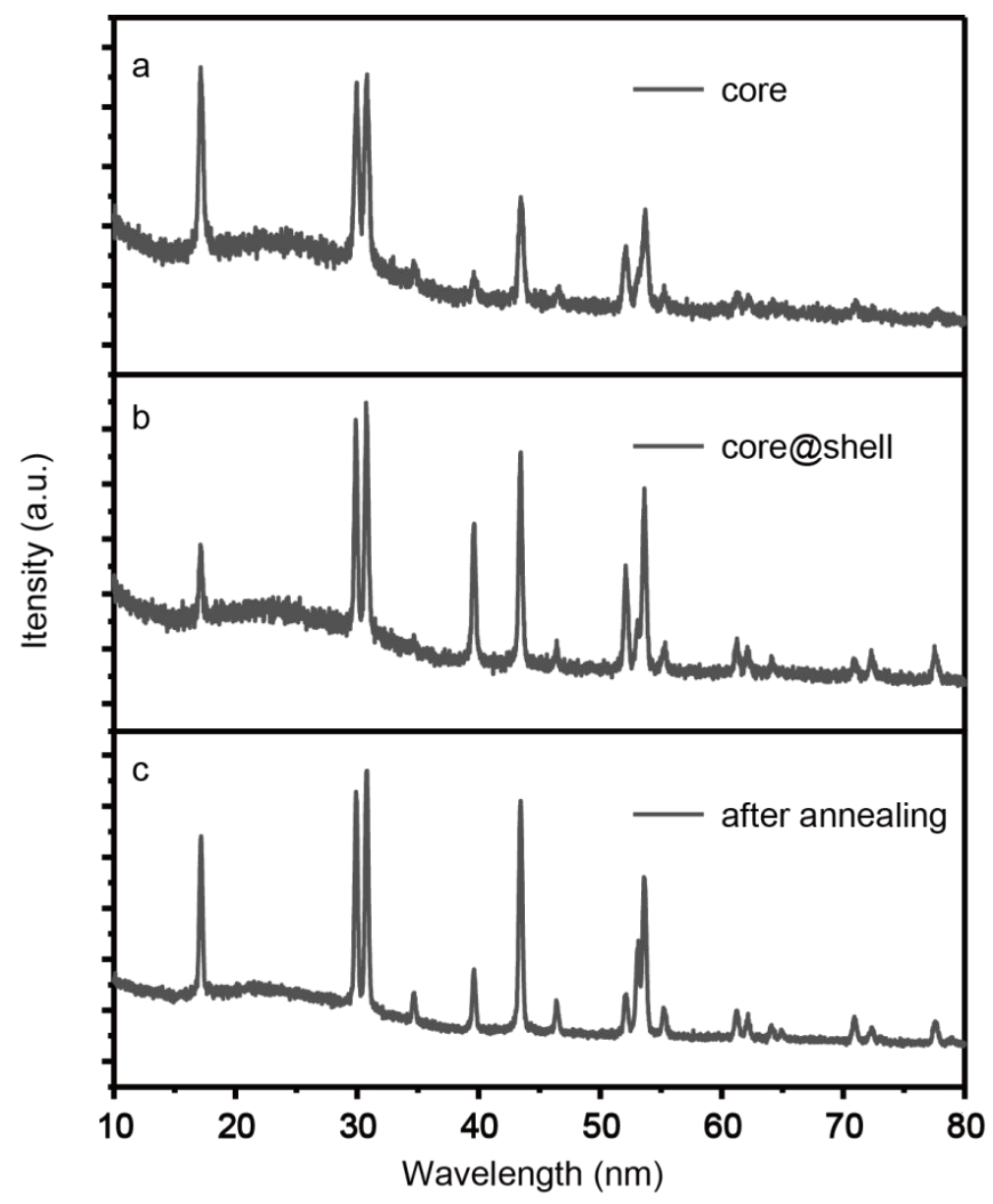

Figure S3. XRD patterns of $\mathrm{NaErF}_{4}$ core, $\mathrm{NaErF}_{4} @ \mathrm{NaYF}_{4}$ core/shell, $\mathrm{NaErF}_{4} @ \mathrm{NaYF}_{4}$ core/shell nanoparticles after post annealing for $12 \mathrm{~h}$. It can be seen that the highly crystalline hexagonal phase of the nanoparticles is maintained very well after the post annealing treatment. 

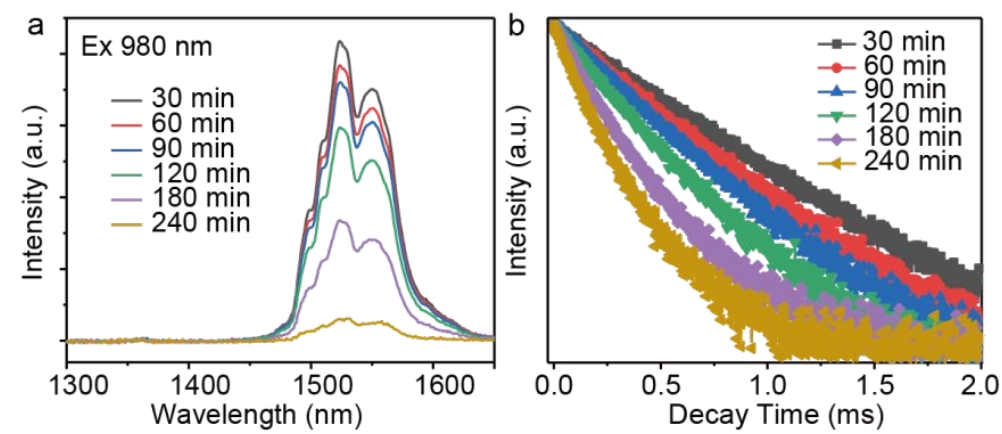

Figure S4. The evolution of NIR emission spectra and time decay curves at $1530 \mathrm{~nm}$ of $\mathrm{NaErF}_{4} @ \mathrm{NaYF}_{4}$ nanoparticles (core size: $19.6 \mathrm{~nm}$; shell thickness: $1.2 \mathrm{~nm}$ ) during the post annealing progress in the solution at $280{ }^{\circ} \mathrm{C}$. The NIR emission at $1530 \mathrm{~nm}$ gradually decreased as increasing of the post annealing time, indicating the $\mathrm{Er}^{3+}$ migrate from the $\mathrm{NaErF}_{4}$ inner core to $\mathrm{NaYF}_{4}$ shell and further induced the quenching of $\mathrm{Er}^{3+}$ dominated luminescence. Because of break over of the energy transfer between the inside $\mathrm{Er}^{3+}$ activators and surface quenchers, the life time of the NIR emission sharply decreased. 

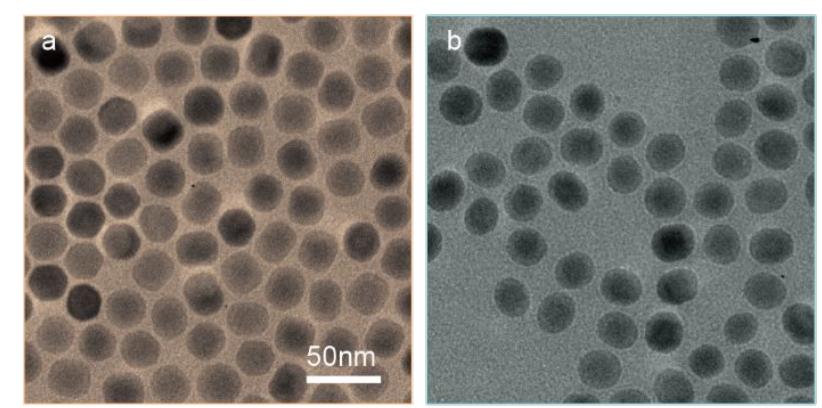

Figure S5. TEM images of the obtained $\mathrm{NaErF}_{4} @ \mathrm{NaYF}_{4}$ core/shell structured nanoparticles with a shell thickness of $5.3 \mathrm{~nm}$ before and after post annealing treatment in the solution at $280{ }^{\circ} \mathrm{C}$ for $12 \mathrm{~h}$. The size and morphology of the core/shell nanoparticles are maintained very well before and after the annealing. The molar ratio between the $\mathrm{Y}^{3+}$ and $\mathrm{Er}^{3+}$ in the $\mathrm{NaErF}_{4} / \mathrm{NaYF}_{4}$ core/shell nanoparticles are monitored by ICP-MS during the annealing process. The results show that the molar ratio between the $\mathrm{Y}^{3+}$ and $\mathrm{Er}^{3+}$ in the core/shell nanoparticles are nearly unchanged before (2.4) and after post annealing (2.3). So we can exclude the dissolution of lanthanide ions from the nanoparticles into the solution during our post annealing process.

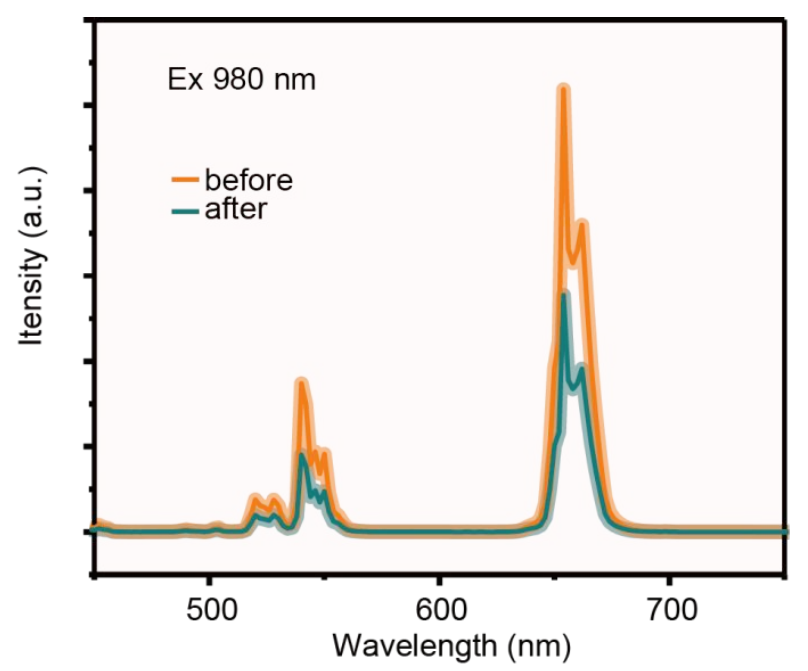

Figure S6. Upconversion emission spectra of the $\mathrm{NaErF}_{4} @ \mathrm{NaYF}_{4}$ core/shell nanoparticles under the excitation of $980 \mathrm{~nm}$ before and after post annealing treatment at $280{ }^{\circ} \mathrm{C}$ for $12 \mathrm{~h}$. 


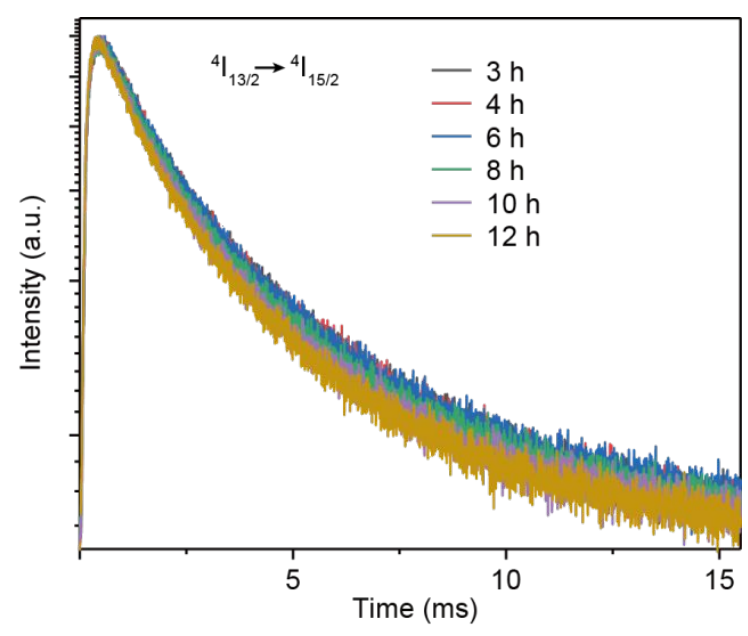

Figure S7. The time decay curves at 1530 nm of $\mathrm{NaErF}_{4} @ \mathrm{NaYF}_{4}$ nanoparticles (core size: $19.6 \mathrm{~nm}$; shell thickness: $5.3 \mathrm{~nm}$ ) during the post annealing progress in the solution at $280{ }^{\circ} \mathrm{C}$. The lifetime of the emission at $1530 \mathrm{~nm}$ dominated by $\mathrm{Er}^{3+}$ is gradually decreased during the post annealing progress, demonstrating the energy transfer from the activators in the inner core to the surface defects. Compared with the $\mathrm{NaErF}_{4} @ \mathrm{NaYF}_{4}$ nanoparticles with thin $\mathrm{NaYF}_{4}$ shell (1.2 nm, Figure S4b), the amplitude of lifetime reduction is greatly decreased, indicating that the thick shell can effectively inhibit the break over of the energy transfer between the inside $\mathrm{Er}^{3+}$ activators and surface quenchers during the post annealing progress. 


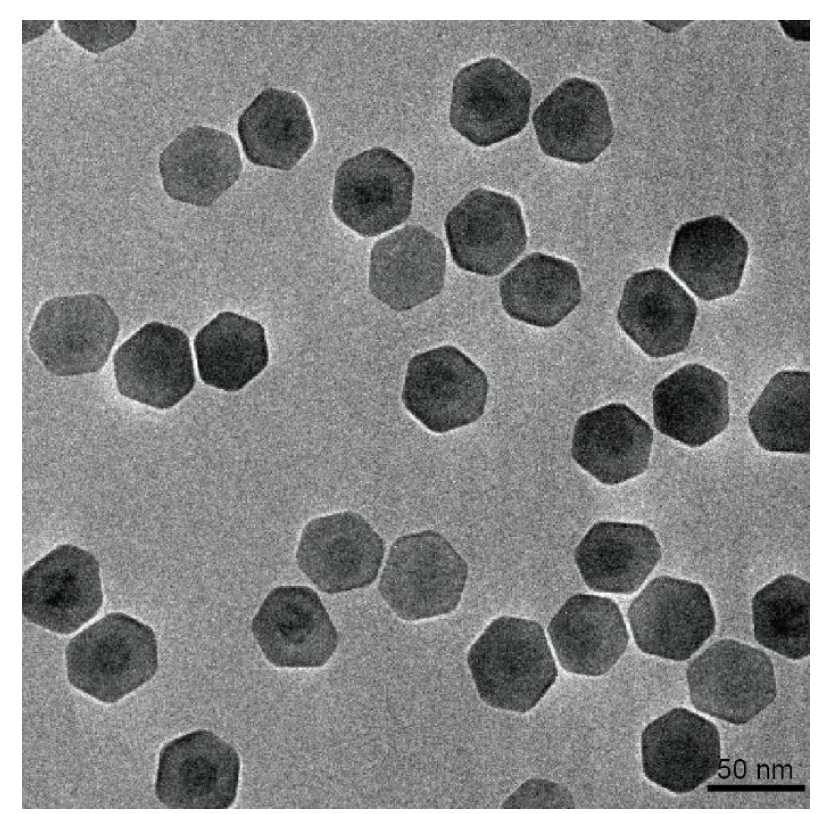

Figure S8. TEM image of the $\mathrm{NaErF}_{4} @ \mathrm{NaYF}_{4}$ core/shell nanoparticles with a shell thickness of $10.2 \mathrm{~nm}$.
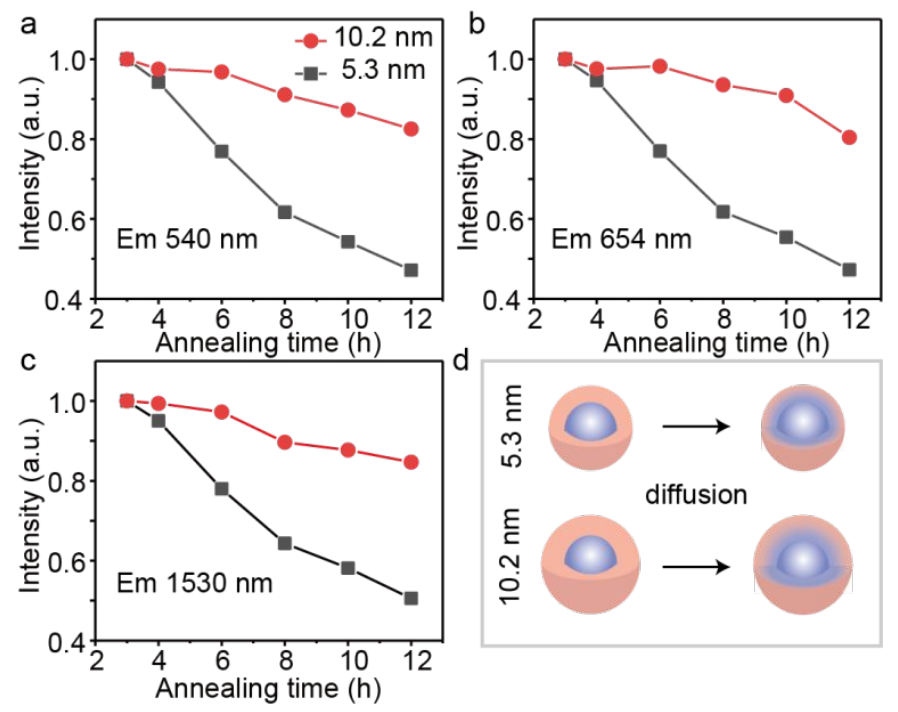

Figure S9. Normalized intensity of the upconversion emission at $540 \mathrm{~nm}(\mathrm{a}), 654 \mathrm{~nm}$ (b) and down-shifting emission at $1530 \mathrm{~nm}$ (c) of $\mathrm{NaErF}_{4} @ \mathrm{NaYF}_{4}$ core/shell nanoparticles with different shell thickness (red: $10.2 \mathrm{~nm}$; black: $5.3 \mathrm{~nm}$ ) at different post annealing time. (d) Schematic of $\mathrm{Er}^{3+}$ ions distribution in $\mathrm{NaErF}_{4} @ \mathrm{NaYF}_{4}$ nanoparticles with different shell thickness after post annealing treatment. The descending speed of the emissions from $\mathrm{NaErF}_{4} @ \mathrm{NaYF}_{4}$ nanoparticles decreased as increasing of the shell thickness, indicating that the migration of $\mathrm{Er}^{3+}$ from inner core to outer shell can be greatly inhibited by increasing the thickness of the $\mathrm{NaYF}_{4}$ passivation shell. 

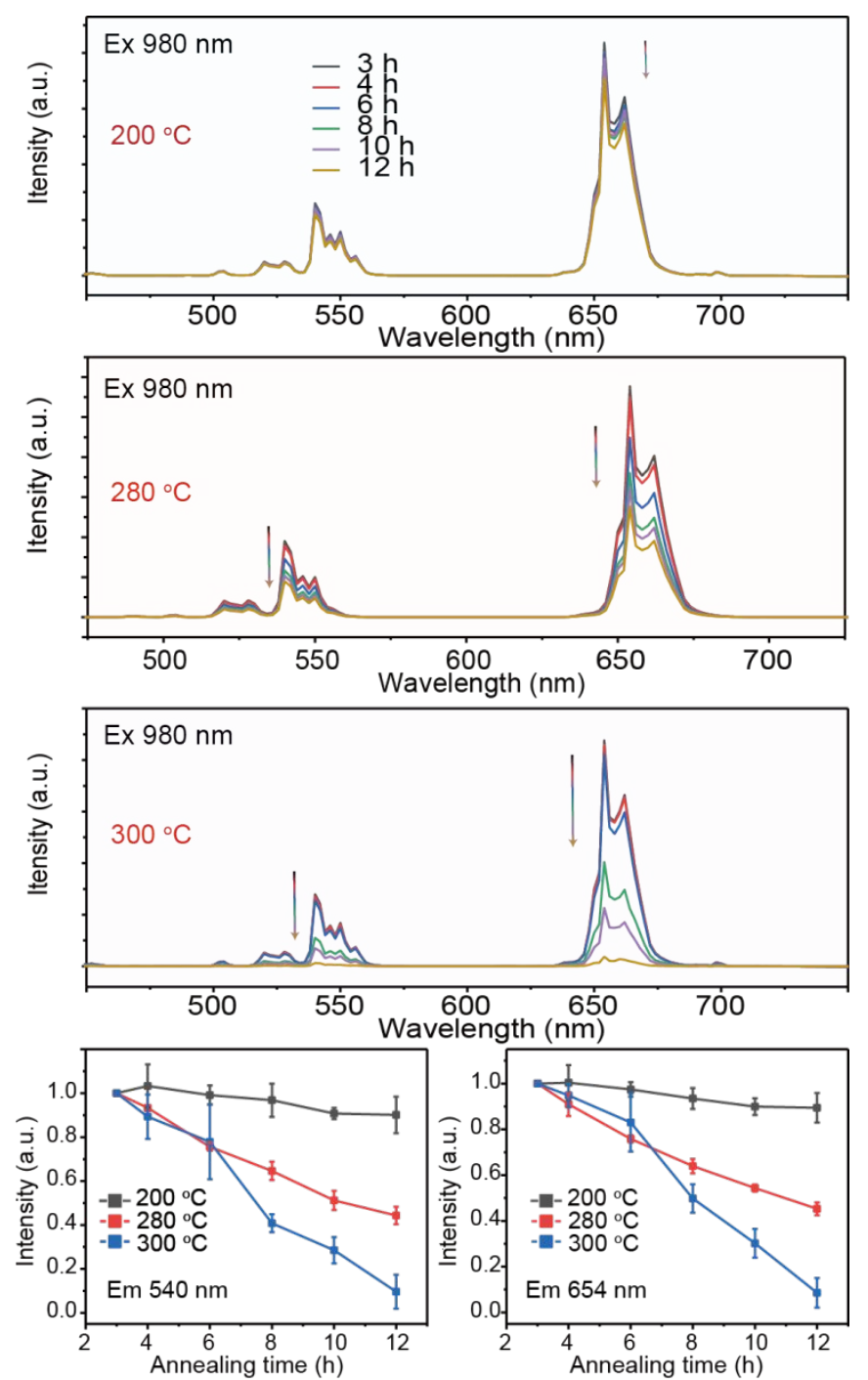

Figure S10. The evolution of upconversion emission spectra of $\mathrm{NaErF}_{4} @ \mathrm{NaYF}_{4}$ core/shell nanoparticles under the excitation of $980 \mathrm{~nm}$ during the post annealing progress in the solution at $200{ }^{\circ} \mathrm{C}(\mathrm{a}), 280{ }^{\circ} \mathrm{C}(\mathrm{b})$ and $300{ }^{\circ} \mathrm{C}(\mathrm{c}) .(\mathrm{d}$, e) Normalized intensity of the upconversion emission at $540 \mathrm{~nm}$ (d) and 654 nm (e) of $\mathrm{NaErF}_{4} @ \mathrm{NaYF}_{4}$ core/shell nanoparticles at different temperature and post annealing time. 

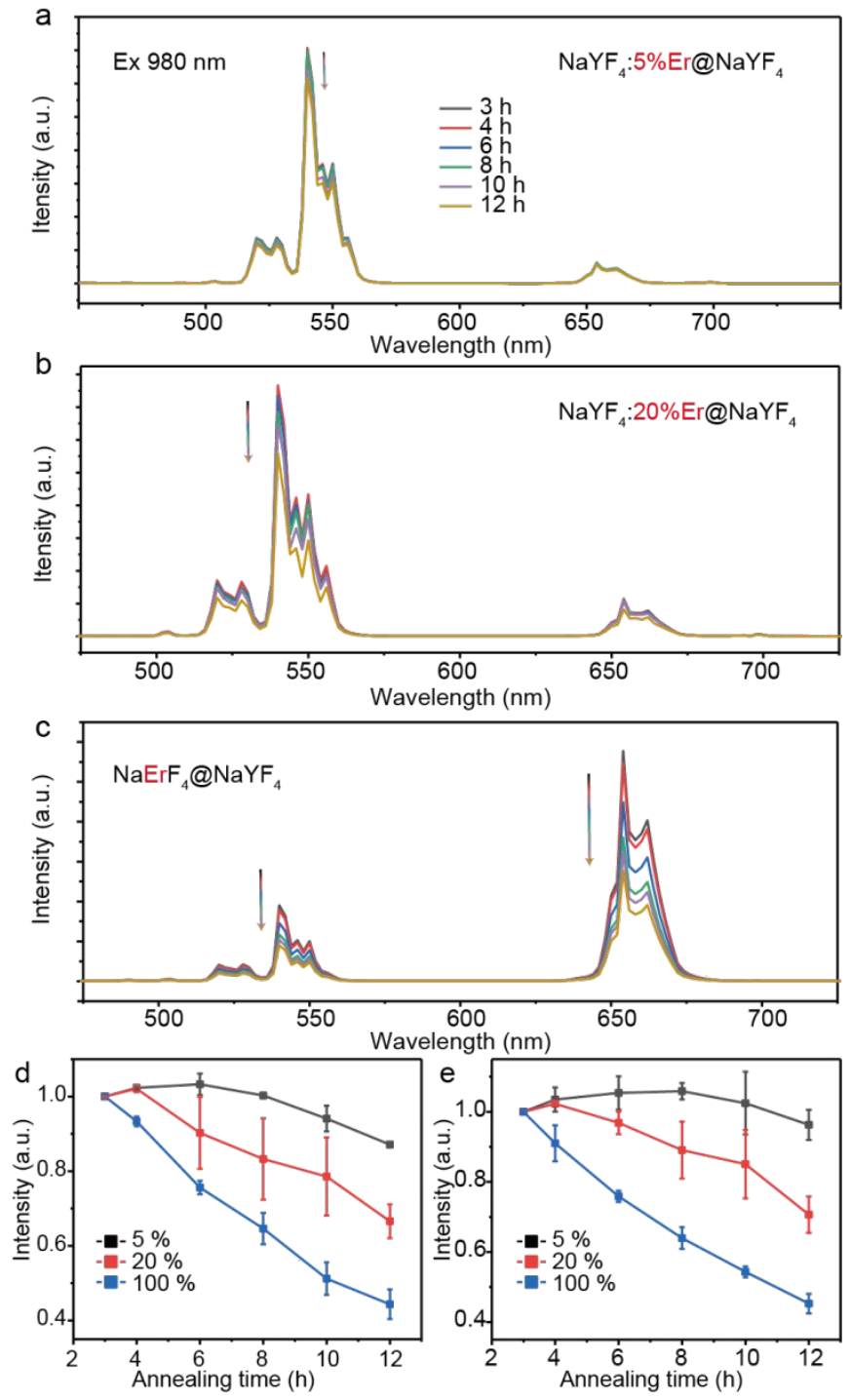

Figure S11. The evolution of upconversion emission spectra of $\mathrm{NaYF}_{4}: \mathrm{x} \% \mathrm{Er} @ \mathrm{NaYF}_{4}$ core/shell nanoparticles with different $\mathrm{Er}^{3+}$ doping concentrations (a, $5 \%$; b, $20 \%$; , $100 \%$ ) in the inner core during the post annealing progress at $280{ }^{\circ} \mathrm{C}$. (d) Normalized intensity of the upconversion emission at $540 \mathrm{~nm}$ (d) and $654 \mathrm{~nm}$ (e) of $\mathrm{NaYF}_{4}: \mathrm{x} \% \mathrm{Er} @ \mathrm{NaYF}_{4}$ core/shell nanoparticles at different post annealing time. 

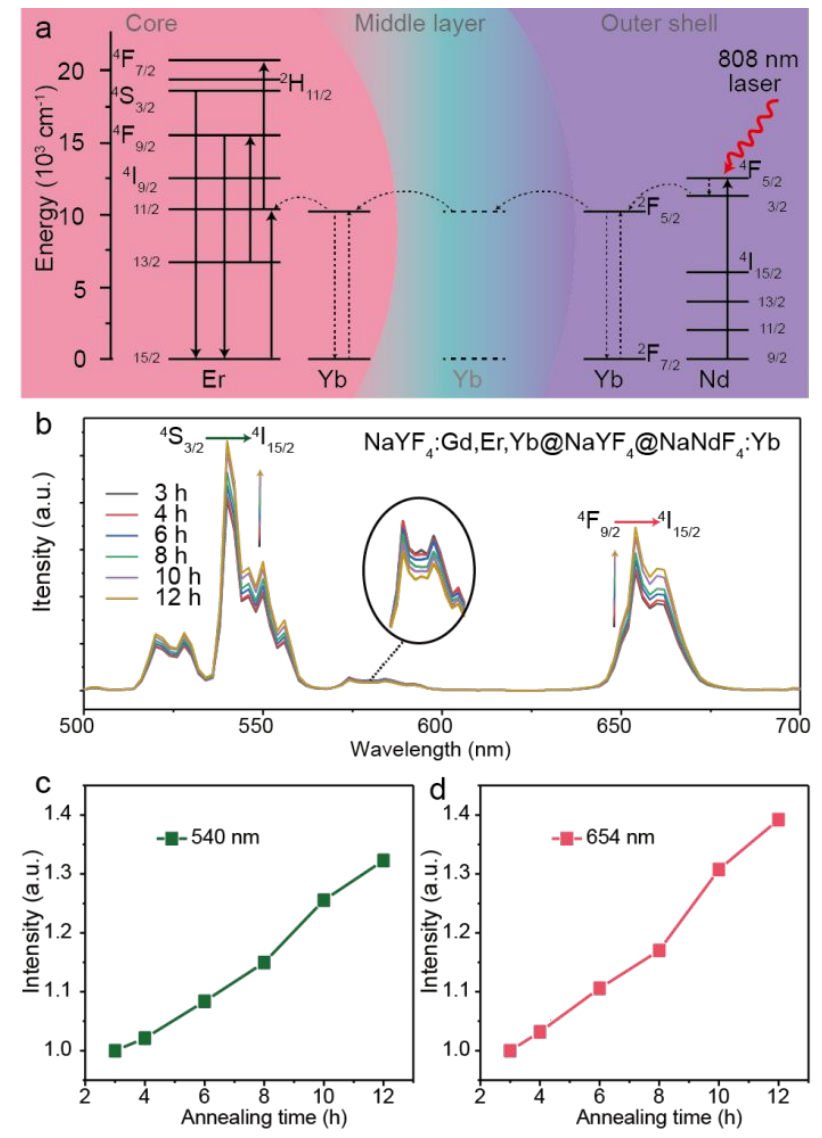

Figure S12. (a) Scheme illustration of the energy transfer in the core/shell/shell structured $\mathrm{NaYF}_{4}: \mathrm{Gd}, \mathrm{Yb}, \mathrm{Er} @ \mathrm{NaYF}_{4} @ \mathrm{NaNdF}_{4}: \mathrm{Yb}$ nanoparticles. (b) The evolution of upconversion emission spectra of $\mathrm{NaYF}_{4}: \mathrm{Gd}, \mathrm{Yb}, \mathrm{Er} @ \mathrm{NaYF}_{4} @ \mathrm{NaNdF}_{4}: \mathrm{Yb}$ nanoparticles during the post annealing progress in the solution at $280{ }^{\circ} \mathrm{C}$. (c, d) Normalized intensity of the upconversion emission at $540 \mathrm{~nm}$ (c) and $654 \mathrm{~nm}$ (d) of $\mathrm{NaYF}_{4}: \mathrm{Gd}, \mathrm{Yb}, \mathrm{Er} @ \mathrm{NaYF}_{4} @ \mathrm{NaNdF}_{4}: \mathrm{Yb}$ core/shell nanoparticles at different post annealing time. It can be seen that the intensity of green $(540 \mathrm{~nm})$ and red $(654 \mathrm{~nm})$ emission bands dominated by $\mathrm{Er}^{3+}$ increased as the prolonging of annealing time, while the emission band at $\sim 580 \mathrm{~nm}$ dominated by $\mathrm{Nd}^{3+}$ decreased. During the post annealing process, $\mathrm{Yb}^{3+}$ ions in $\mathrm{NaYF}_{4}: \mathrm{Gd}, \mathrm{Yb}, \mathrm{Er}$ core and $\mathrm{NaNdF}_{4}: \mathrm{Yb}$ outer layer gradually migrate into the inert $\mathrm{NaYF}_{4}$ transition layer, which result in the enhanced energy transfer from $\mathrm{Nd}^{3+}$ in the outer layer to the $\mathrm{Er}^{3+}$ ions in the core, and further induced the increasing of emissions dominated by $\mathrm{Er}^{3+}$. Although the energy transfer mechanism in the core/multi-shell structured $\mathrm{NaYF}_{4}: \mathrm{Gd}, \mathrm{Yb}, \mathrm{Er} @ \mathrm{NaYF}_{4} @ \mathrm{NaNdF}_{4}: \mathrm{Yb}$ and $\mathrm{NaYF}_{4}: \mathrm{Gd}, \mathrm{Yb}, \mathrm{Ho} @ \mathrm{NaYF}_{4} @ \mathrm{NaNdF}_{4}: \mathrm{Yb}$ nanoparticles (Figure 6) is the same, the energy transfer efficiency are quite different for the two structures. The intensity ratio 
between the $\mathrm{Er}^{3+}$ dominated emission at $\sim 540 \mathrm{~nm}$ and $\mathrm{Nd}^{3+}$ dominated emission at $~$ $580 \mathrm{~nm}$ (Figure S12b, 16.5) is much higher than that of between the $\mathrm{Ho}^{3+}$ dominated emission at $\sim 540 \mathrm{~nm}$ and $\mathrm{Nd}^{3+}$ dominated emission at $\sim 580 \mathrm{~nm}$ (Figure $6 \mathrm{~b}, 3.6$ ), indicating that the $\mathrm{Nd}^{3+} \rightarrow \mathrm{Yb}^{3+} \rightarrow \mathrm{Er}^{3+}$ energy transfer efficiency in the $\mathrm{NaYF}_{4}: \mathrm{Gd}, \mathrm{Yb}, \mathrm{Er} @ \mathrm{NaYF}_{4} @ \mathrm{NaNdF}_{4}: \mathrm{Yb}$ is much higher than the $\mathrm{Nd}^{3+} \rightarrow \mathrm{Yb}^{3+} \rightarrow \mathrm{Ho}^{3+}$ energy transfer efficiency in the $\mathrm{NaYF}_{4}: \mathrm{Gd}, \mathrm{Yb}, \mathrm{Ho} @ \mathrm{NaYF}_{4} @ \mathrm{NaNdF}_{4}: \mathrm{Yb}$. 

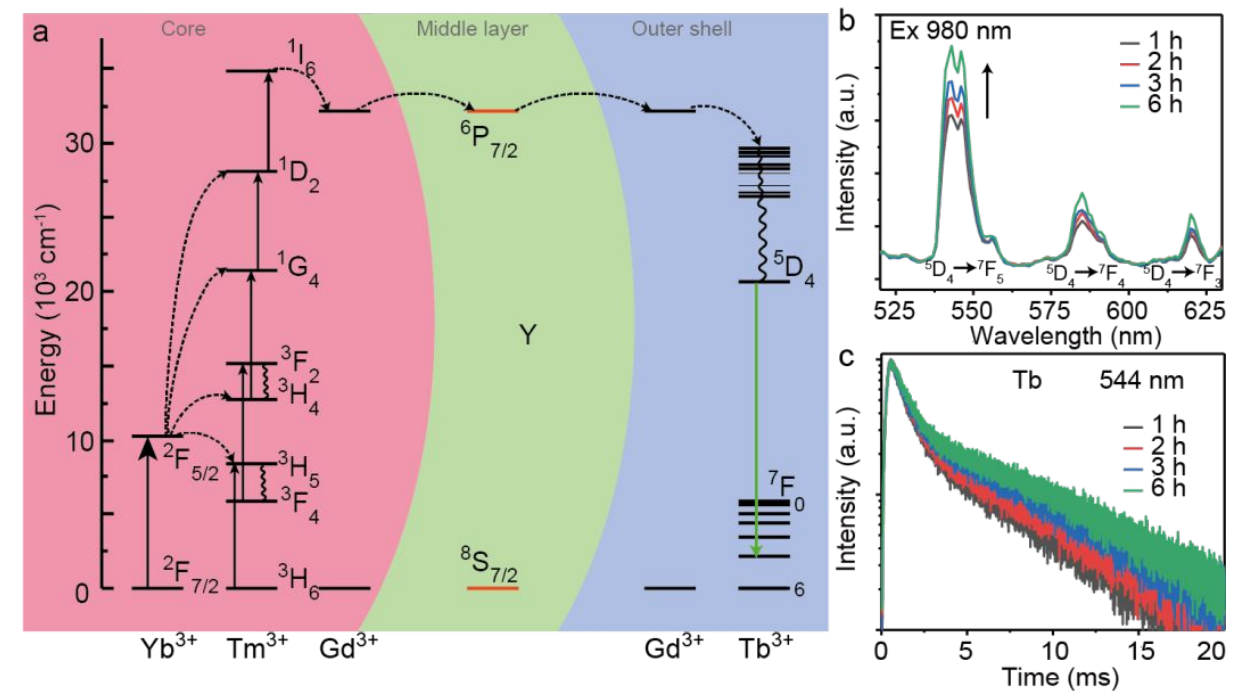

Figure S13. (a) Scheme illustration of the energy transfer in the core/shell/shell structured $\mathrm{NaGdF}_{4}: \mathrm{Yb}, \mathrm{Tm} @ \mathrm{NaYF}_{4} @ \mathrm{NaGdF}_{4}: \mathrm{Tb}$ nanoparticles. $\mathrm{Yb}^{3+}$ ions in the core are used as sensitizer to harvest the $980 \mathrm{~nm}$ excitation light. The $\mathrm{Tm}^{3+}$ ions are introduced to extract the excitation energy from $\mathrm{Yb}^{3+}$ and generate the high-lying energy states. A migrator $\mathrm{Gd}^{3+}$ extracts the excitation energy from high-lying energy states of $\mathrm{Tm}^{3+}$, followed by transferring the energy to $\mathrm{Tb}^{3+}$. Then, $\mathrm{Tb}^{3+}$ dominated upconversion emissions can be obtained. ${ }^{[2]}$ (b) The evolution of upconversion emission spectra of $\mathrm{NaGdF}_{4}: \mathrm{Yb}, \mathrm{Tm} @ \mathrm{NaYF}_{4} @ \mathrm{NaGdF}_{4}: \mathrm{Tb}$ nanoparticles during the post annealing progress in the solution at $280{ }^{\circ} \mathrm{C}$. (c) The time decay curves at $544 \mathrm{~nm}$ dominated by $\mathrm{Tb}^{3+}$ during the post annealing progress in the solution at $280{ }^{\circ} \mathrm{C}$. It can be seen that the intensity of emission at $544 \mathrm{~nm}$ dominated by $\mathrm{Tb}^{3+}$ increased as the prolonging of annealing time. During the post annealing process, $\mathrm{Gd}^{3+}$ ions in $\mathrm{NaGdF}_{4}: \mathrm{Yb}, \mathrm{Tm}$ core and $\mathrm{NaGdF}_{4}: \mathrm{Tb}$ outer layer gradually migrate into the inert $\mathrm{NaYF}_{4}$ transition layer, which result in the enhanced energy transfer from $\mathrm{Tm}^{3+}$ in the inner core to the $\mathrm{Tb}^{3+}$ ions in the outer shell, and further induced the increasing of intensity and life time of the emissions dominated by $\mathrm{Tb}^{3+}$. 

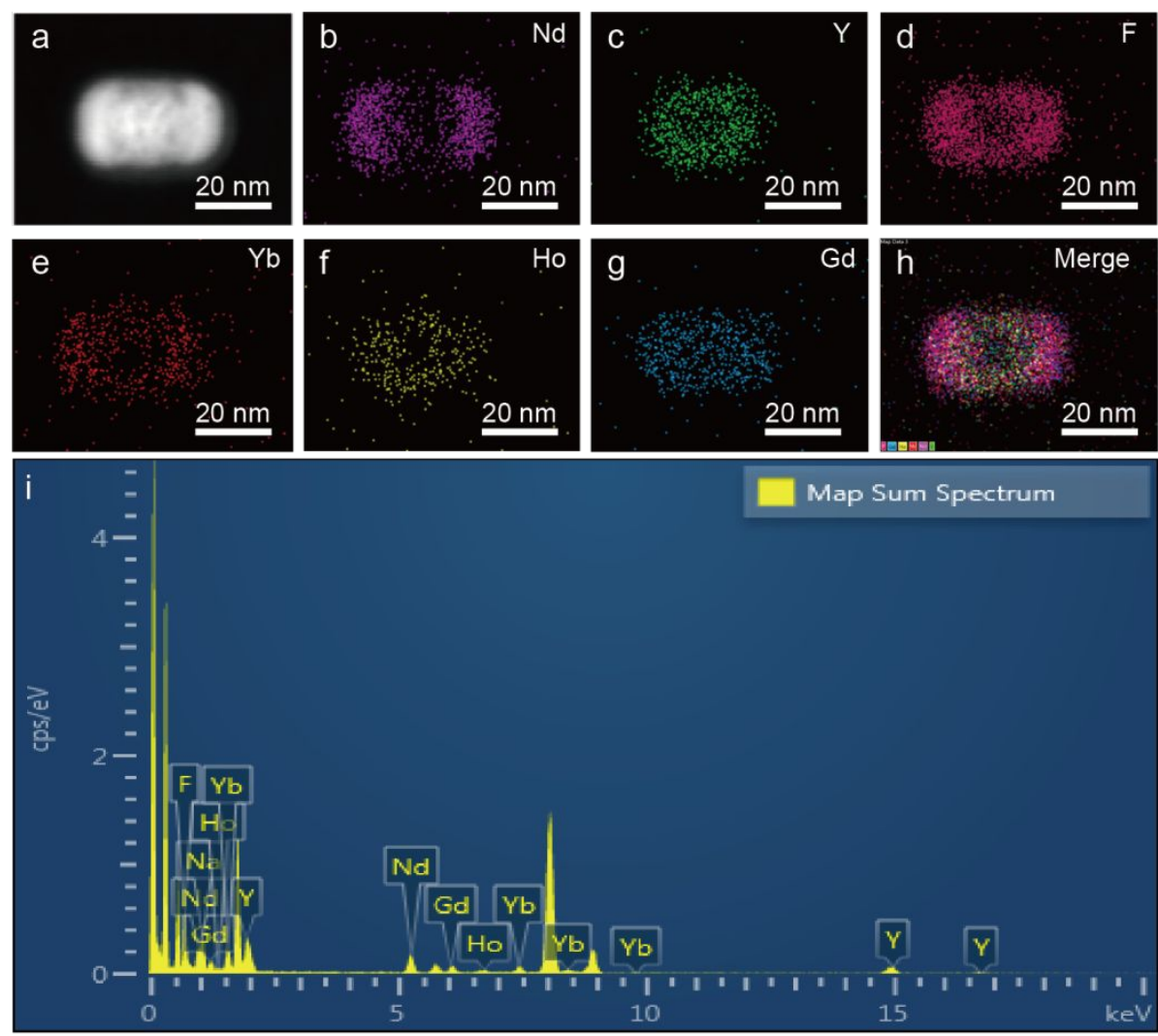

Figure S14. High-angle annular dark field scanning transmission electron microscopy (a), elemental mapping (b-h), and energy dispersive X-ray analysis (i) of $\mathrm{NaYF}_{4}: \mathrm{Gd}, \mathrm{Yb}, \mathrm{Ho} @ \mathrm{NaYF}_{4} @ \mathrm{NaNdF}_{4}: \mathrm{Yb}$ nanoparticles. 


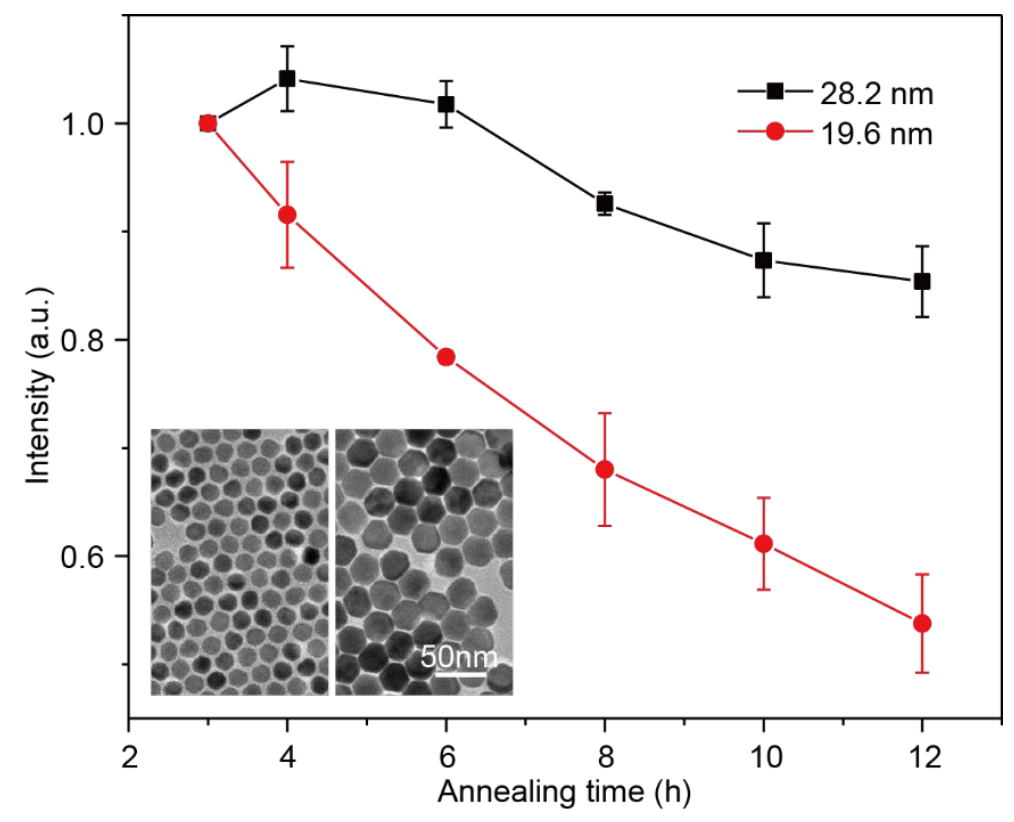

Figure S15. Normalized intensity of the emission at 1530 nm of $\mathrm{NaErF}_{4} @ \mathrm{NaYF}_{4}$ core/shell nanoparticles with different core nanoparticles (red: $19.6 \mathrm{~nm}$; black: $28.2 \mathrm{~nm}$ ) at different post annealing time. Insert: TEM images of $\mathrm{NaErF}_{4}$ core nanoparticles with different size. The shell thickness is $\sim 5.3 \mathrm{~nm}$.

\section{References}

[1] F. Wang, R. Deng, X. G. Liu, Nat Protoc. 2014, 9, 1634.

[2] F. Wang, R. Deng, J. Wang, Q. Wang, Y. Han, H. Zhu, X. Chen, X. Liu, Nat. Mater. $2011,10,968$. 